\title{
REFLEXIONES SOBRE LA EPISTEMOLOGÍA DEL TURISMO
}

\author{
Francisco MUÑOZ DE ESCALONA \\ CSIC (España) \\ mescalafuen@telefonica.net
}

\section{CONCERNS AROUND THE EPISTEMOLOGY OF TOURISM}

Resumen: Al estudio del turismo se destinan desde hace varias décadas ingentes recursos materiales y personales. Se ha convertido hoy en la dedicación de una pléyade de estudiosos de muy desigual nivel de preparación. Lo mismo cabe decir de los centros que se ocupan de desarrollar estos estudios y, como cabía esperar, de las empresas editoriales que están al servicio de difundir los resultados de los mismos. Hay quien cree que esta sobreabundancia de centros y editoriales evidencia que, por fin, se ha alcanzado ya la tan ansiada meta de su cientificación. Los asuntos tratados por los estudiosos son cada vez más variados. Se diría que se aspira a crear un mundo que refleje y duplique el mundo convencional. No es de extrañar por ello que si existe la filosofía se ofrezca en paralelo una filosofía del turismo y, por idénticas razones, una biología del turismo o una arqueología del turismo. Y así en todos los demás aspectos en los que se diversifica el mundo. Entre ellos ha surgido hace pocos años la eventual necesidad de una epistemología del turismo. Sobre ambas cuestiones, la epistemología y el turismo, se pronuncia el presente trabajo.

Abstract: The individual and material resources are moved to the study of tourism from many decades on. Today, this happens because tourism became in an attractive source for research. The same applies for the centres of investigation as well as the editorial publishers that are aimed at disseminating their resulted knowledge. The overabundance of tourism research and its publication evidences a point of maturity, some scholars preclude. This exhibits a type of scientificization, which rests on shaky foundations. One of the epistemological problems of tourism research is the decentralization of the themes to study. Not surprisingly, a spirit of tourism alludes to the formulation of a philosophy of tourism, and for that the creation of a new biology of the industry to scatter the knowledge. To what an extent, we need the creation of an epistemology of tourism this essay review triggers a new fresh discussion.

Palabras clave: Turismo; Masificación; Tiempo libre; Complejidad; Epistemología Tourism,; Massification; Leisure time; Complexity; Epistemology 


\section{Una inquietante cuestión, el turismo}

"La noción de turismo es tan compleja como definir el color del viento". (Notion complexe que celle du tourisme: couleur de vent) Con esta lapidaria frase expresó genialmente Paul Ossipow, en 1951, uno de los tópicos más querido por los turisperitos el de que el turismo es una realidad sumamente compleja, inasible y escurridiza. La frase alude con ironía a que la doctrina convencional no consigue ofrecer una interpretación convincente de la realidad. Ossipow criticó acerbamente esta incapacidad y propuso una visión menos restrictiva del turismo lo que le costó la solemne e inmerecida reprimenda del gurú indiscutido de su tiempo, el economista suizo Kurt Krapf (1954). La frase de Ossipow continúa así: "Un día se acuerda ver en él una ciencia y al día siguiente se le ve como un mero hecho, un conjunto de actos. Y es que el turismo es las dos cosas a la vez, pues el turismo es un fenómeno que consiste, esencialmente, en los desplazamientos humanos cuya repetición, frecuencia e importancia han terminado por dar lugar a su estudio sistemático y objetivo" (Ossipow, 1951: 71-73).

Ossipow denunciaba así, hace más de medio siglo, la desorienta y confusa actitud por parte de los estudiosos, los cuales explicaban entonces y siguen explicando hoy el turismo por medio de un abigarrado corpus de doctrinas que se han ido acumulando de modo aluvial desde finales del siglo XIX. El turismo sigue siendo entendido básicamente como lo que hacen los turistas, pero la noción de turista se ha manoseado tanto que, a la postre, sigue quedando confusa. No queda aquí la cosa porque los estudiosos también llaman turismo a todo aquello que se relaciona de cualquier forma con los turistas, sean estos lo que sean, desde los medios de hospitalidad hasta los medios de transporte, desde los museos a los lagos, desde los eventos a las ruinas de la antigüedad, es decir, a todo ese variopinto conjunto de cosas que se comportan como facilitadoras e incentivadores de las visitas, unas visitas que lo mismo son genéricas que específicas. En la costumbre de designar con el sustantivo turismo a las realidades citadas radican en gran parte las razones que llevan a los turisperitos a insistir incansablemente en la supuesta complejidad extrema de la realidad estudiada bajo las tres dimensiones citadas. Unas veces, como dice Ossipow (ob. cit.), se refieren a los hechos y otras a su interpretación, pero no resulta fácil saber cuándo hablan de unos o de otra. No se percatan de que, como enseña Karl R. Popper (1986), hay que distinguir entre tres mundos diferentes, el de los hechos (lo que llamamos realidad), el de la interpretación de esos hechos (las teorías que tratan de explicarlos) y el de los sentimientos humanos (los afectos) y que cada uno de ellos ha de ser estudiado en sí mismo y al margen de los otros.

¿Quieren una prueba de que con el nombre turismo los turisperitos aluden al corpus teórico antes que a la realidad? Basta con aducir que para ellos el turismo existe desde que existe la palabra turismo. Deben pensar, como en la Biblia, que en el principio era el verbo. Quiero decir que antes de que surgiera la palabra turismo no podía haber turismo. En algo llevan razón quienes así piensan, y eso es ya una pista que merece ser roturada. Como sabemos, con el vocablo turismo aludimos a un fenómeno social, un fenómeno que se manifiesta por medio de la masificación de los viajes de placer. Por turismo entendemos esa masificación. Antes fue el tour y después el turismo como realidad social y como realidad económica. No obstante, ello no impide a los turisperitos ni al hablante decir que una persona que hace un viaje de placer hace turismo. Deberíamos decir que participa del turismo, porque quien hace turismo es un colectivo, nunca el individuo. La cuestión radica, pues, en indagar desde cuando se hacen viajes de placer de forma masiva. Entre las respuestas a esta cuestión las hay para todos los gustos. Hay quien sostiene que el turismo tiene la edad de la especie humana. Los que así piensan creen que el turismo consiste en desplazarse por el territorio y que desde sus comienzos el hombre se mueve por el territorio por numerosos motivos, entre ellos el del placer. Otros autores como Maximiliano Korstanje, concibe que vincular al turismo con la movilidad es un legado cultural de la mitología nórdica, ese conjunto de relatos fantásticos que reflejan 
las costumbres de los pueblos paganos. Según Korstanje, "cualquiera se puede divertir (tomar distancia en un viaje) incluso en uno antropológico, pero eso no es turismo. El turismo tiene tres elementos: a) desplazamiento normativo con fines lúdicos, b) hospitalidad, y c) retorno" (Korstanje, 2008; Thirkettle y Korstanje, 2013; Korstanje, 2012). El ocio, sigue Korstanje, es un proceso de ruptura y el turismo era parte del ocio. El Grand Tour era muy parecido a lo que hoy es un viaje de egresados, un ritual de pasaje que marcaba la madurez del soberano. Tenía los tres elementos del turismo: desplazamiento lúdico, hospitalidad y retorno. En los viajes de negocios solo responde a la necesidad de segmentar un mercado. No una naturaleza nueva de desplazamiento" (Korstanje, 2011; 2012).

La aparición del vocablo turismo en la segunda mitad del siglo XIX ha conducido a sostener que el turismo existe desde entonces. Hay posturas más radicales, entre ellas merece ser citada la del sociólogo francés J. Dumazedier (1968), para quien el turismo es una realidad social harto reciente, tanto que no aparece hasta la segunda mitad del siglo XX. Y es que el tour (el viaje de placer con vuelta) es anterior al turismo (la generalización o masificación de los viajes de placer). El tour (viaje con vuelta) existe desde hace cuatro o cinco mil años, desde que surgieron los asentamientos humanos de cierta entidad, pero el vacacionismo tardó en masificarse y es muy reciente, quizás no tanto como sostiene Dumazedier pero podríamos remontarlo a mediados del XIX, coincidiendo con la creación de la agencia de Thomas Cook. Por esta razón no es correcto hablar, como es frecuente hoy, de turismo espacial por el mero hecho de que se hayan empezado a ofrecer viajes de placer a $100 \mathrm{~km}$. de distancia de la Tierra. Para que estos viajes se masifiquen tendrán que pasar algunos años, tal vez tantos como los que han tenido que pasar para que haya turismo terrenal ${ }^{1}$.

¿A qué se refieren los turisperitos cuando dicen que el turismo es una cuestión presentada como algo tan extremadamente complejo e indefinible que Ossipow lo comparó irónicamente con el color del viento? ¿Llama la turispericia turismo a los desplazamientos masivos de placer, a los que deberíamos llamar mejor vacacionismo? ¿O se refieren al corpus teórico acumulado por aluvión desde finales del siglo XIX lo que los lleva a blasonar que ya se ha alcanzado su plena cientificación, que hay una nueva ciencia específica, autónoma e independiente de las demás a la que llaman turismología? Porque si se refieren a los hechos, es decir, a la realidad, no cabe duda de que su presunta complejidad varía de nula a inconmensurable. Nula, porque esa realidad nos puede entrar por los ojos y por ello nos puede parecer tan clara como el agua o tan incolora como el viento. Pero es que también nos puede parecer inconmensurable si aspiramos, como propone la turispericia, a explicarla holísticamente, tratando de indagar por qué el hombre aspira a divertirse cambiando estacionalmente de lugar, o por qué complejas razones siente una curiosidad incontenible por lo exótico, pintoresco, extraño o misterioso.

El turismo como realidad fenoménica es, sin duda, un mundo extremadamente complejo como toda realidad es compleja y más aun si esa realidad que pretendemos conocer es social como lo es el turismo. Pero el turismo, como interpretación teórica y sistematizada, no tiene por qué ser complejo si es que se atiene a las reglas establecidas para la construcción de una interpretación tan sólida como sea posible para ponerlo a servicio de las necesidades humanas. Ha sido el academicismo galopante que se ha adueñado de la investigación de esta parcela de la realidad social lo que lo presenta como una realidad compleja cuando lo complejo es el corpus resultante de una investigación encorsetada, la cual no busca la utilidad de

1 Copiamos esta nota de prensa aparecida en www.elpais.com el 15 de diciembre de 12013: Ahora llega la alternativa europea, de la mano de una empresa Suiza, S-3, que, en colaboración de una docena de empresas aeroespaciales, incluidas cuatro españolas, apunta hacia la explotación turística del espacio y con el puerto espacial correspondiente en Canarias. El primer objetivo de S-3 (Swiss Space System) es ofrecer puesta en órbita de satélites, de unos 250 kilos, a bajo coste y partiendo de la superficie terrestre con un avión comercial modificado en lugar de un cohete. Pero si todo sale bien, enseguida se adaptará la nave espacial en que se basa el sistema para embarcar pasajeros (cuatro y dos pilotos) y llevarlos hasta la frontera de 100 kilómetros para asomarse al espacio en una experiencia que durará hora y media en total, con 15 o 20 minutos flotando arriba. 
la explicación sino la construcción de tantas explicaciones como disciplinas se cultivan en los centros universitarios. Los investigadores se enfrentan al turismo como si fuera el reflejo del mundo con todas sus dimensiones y complejidades. De aquí que el turismo tenga su filosofía, su biología, su antropología, su arqueología, su economía, su sociología, su geografía, su historia, su psicología...hasta su medicina. Basta echar un vistazo a la bibliografía disponible o al currículo de cualquier centro de enseñanza para percatarse de ello. El egresado en turismo estudia todas esas disciplinas y algunas más, como el marketing, la contabilidad y la dirección de empresas, siendo verdaderamente milagroso que existan en este campo tan buenos y excelentes profesionales a pesar de haber ingerido una dieta disciplinaria tan indigesta. Con una visión más acorde con los hechos y con las necesidades humanas, la interpretación del turismo puede ser perfectamente manejable, definible, entendible y practicable porque partiendo de un nivel menos ambicioso esa interpretación debe aspirar a ser perfectible ateniéndose al rigor científico. Si así se cultiva, el resultado nunca será como el inasible color del viento de Paul Ossipow (ob. cit.). Sobre eso trata la epistemología, sobre la mayor o menor adecuación de la interpretación teórica a la realidad. De eso y no de otra cosa se trata y de eso vamos a tratar.

\section{Los orígenes del turismo}

Comencemos por reflexionar sobre los orígenes del turismo aun a costa de repetir algo que de puro sabido se olvida a menudo. Diremos una vez más que turism es un neologismo inglés derivado de tour, palabra que a su vez deriva del latín tornare, que significa volver. En el siglo XVIII, los ingleses de las clases altas usaban el francés, idioma de la nación que entonces era la primera potencia mundial tanto política como económica y culturalmente. El francés era, y aun sigue siendo hoy aunque menos, el idioma de la diplomacia. Era también el idioma de los ciudadanos más cosmopolitas en un mundo que había elevado las costumbres y la proverbial elegancia de la France a indiscutido paradigma de la distinción y el buen gusto. La nobleza inglesa usaba el verbo to tour con el significado de viajar y el sustantivo tour con el significado de viaje. Bien entendido que no se hacía referencia a cualquier viaje sino a aquellos viajes que hacían los nobles como actividad inherente a su peculiar estatus social, diferenciado del estatus del pueblo llano pero tan rígido y exigente como este. Quiere decirse que con tour no se referían a los viajes de las clases trabajadoras (negociosas), cuyos viajes eran de cariz utilitario, sino a los viajes propios de las clases ociosas (las no trabajadoras). Habida cuenta de que las actividades de las clases ociosas no eran utilitarias, los hablantes las consideraban placenteras, sobre todo cuando la nobleza entró en un proceso de degradación galopante. De ahí que sus viajes fueran tenidos por la sociedad como los viajes de placer por antonomasia, unos viajes que no estaban en absoluto al alcance de los demás. Y, dado que en el siglo XVIII la población inglesa en particular, y la europea en general, era una población que tenía ya a sus espaldas milenios de un sedentarismo cada vez más urbano, por tour se llegó a entender, en coherencia con la etimología del vocablo, un viaje circular o redondo, es decir, un viaje de ida y vuelta, y, en coherencia con la alta condición social de quienes viajaban sin motivos utilitarios, un viaje por placer con vuelta al origen. Así se explica que, cuando apareció el derivado de tour, turism, este se aplicara exclusivamente a los viajes considerados como de ocio a pesar de que, para entonces, el ocio había desaparecido ya del panorama social de los países industrializados para dejar paso, en su lugar, a un simulacro de ocio, al que resulta más adecuado llamar tiempo libre, el tiempo de descanso que dejan las actividades productivas, cada vez más reguladas.

Los nobles que hacían un tour salían de su residencia habitual para volver más pronto que tarde al lugar de partida. Tour alude, pues, como venimos diciendo, al viaje con regreso que se hacía para realizar el tipo de actividades propio de su estatus social: las relaciones sociales, el deporte de la caza, asistir a fiestas palaciegas, visitar a otros nobles. ¿Era turismo lo que hacían los nobles? Para responder a esta pregunta es menester hacer otra. ¿Eran 
masivos los viajes de los nobles? Porque si sus viajes no eran masivos no podían constituir turismo. Por no ser masivos no existía aun una respuesta mercantil, consistente en la aparición de negocios orientados a facilitar esos viajes con fines lucrativos. Los nobles viajaban en sus propios vehículos, iban acompañados de un séquito de sirvientes y se alojaban en las mansiones de sus iguales. De modo y manera que no solo no existía el turismo por parte de la demanda sino que tampoco lo había por parte de la oferta de servicios facilitadores.

Obviamente, el tour es un tipo de viaje que solo lo pueden hacer los pueblos sedentarios ya que el sedentarismo es condición necesaria para que tales viajes puedan hacerse. La cultura sedentaria surgió como consecuencia de la revolución agrícola que tuvo lugar hace diez o doce mil años. Digamos también que si bien tal condición fue necesaria para que apareciera el turismo no fue en absoluto suficiente para su insurgencia ya que los viajes con vuelta exigen disponer de recursos abundantes, tanto que pueden dejar excedentes asignables a la satisfacción de otras necesidades después de quedar cubiertas las necesidades vitales. ¿Cuándo hubo pueblos lo suficientemente ricos como para viajar a lugares distantes y volver al origen? Dar una fecha plausible no es fácil pero sí que podemos pensar que pudo ser a partir del surgimiento de las primeras ciudades, núcleos densamente poblados y por ello con medios generadores de riqueza y por ello dotados ya de clases gobernantes que tenían a su disposición crecientes recursos, recursos que existían gracias al trabajo de las clases negociosas. Nuestra hipótesis consiste en suponer que los miembros de las clases ociosas de antaño fueron los primeros que hicieron viajes de ida y vuelta, unos viajes que haríamos bien en suponer que fueron en primer lugar incursiones armadas en otros territorios en procura de recursos inexistentes en el propio tan valiosos como escasos para cubrir sus necesidades, generalmente de lujo. Se trataría, pues, de desplazamientos con fines bélicos durante siglos, desplazamientos que bien pudieron dar paso mucho después a viajes con fines diplomáticos y, finalmente, a viajes comerciales (inport-export). Sin embargo, erraríamos si dijéramos que el turismo existe desde que hay ciudades, es decir, desde hace unos cinco mil años. Como ya hemos dicho, había tour pero no tourism. Se hacían viajes de ida y vuelta pero durante milenios ni fueron masivos ni se realizaron durante el tiempo libre que dejan las actividades productivas. Estos viajes solo aparecieron como consecuencia de la riqueza generada por las sucesivas revoluciones industriales y las posteriores revoluciones sociales que dignificaron a las clases trabajadoras. La demanda, pues, con su desarrollo, propició la aparición de negocios dedicados a satisfacer las nuevas necesidades. Porque es obvio que antes no existía una respuesta comercial significativa que diera servicios comerciales de transporte y hospitalidad. Las primeras empresas que surgieron fueron las de carruajes y las casas de postas, algunas de las cuales prestaban servicios de transporte y hospedaje. La ausencia primero y después la escasez de servicios facilitadores que ofrecieran niveles de calidad aceptables fue la tónica durante muchas décadas. Hubo que esperar a mediados del XIX para que el transporte ferroviario viniera a revolucionar de forma drástica los desplazamientos terrestres. La nueva oferta vino acompañada de una demanda creciente de viajeros, la cual dio pie al surgimiento de nuevos y mejores establecimientos dedicados a dar servicios de hospitalidad. Con lo que estamos en condiciones de afirmar que hay tourism a partir de mediados del siglo XIX en el sentido de fenómeno social, no en el de actividad personal, condición a la que haremos referencia más adelante.

\section{Dos cuestiones previas sobre el turismo como fenómeno social}

\section{3a. El turismo es cultura y forma parte de la cultura}

Turismo y cultura es uno de los muy abundantes binomios que podemos encontrar en la ingente y tumultuosa literatura que desde hace décadas se escriben sobre el turismo. Tanto se abusa de él que para algunos el turismo es cultura y la cultura es la esencia del turismo. Ya a mediados del siglo XX, los suizos Hunziker y Krapf (1942) sostuvieron sin pestañear que 
el estudio del turismo es en realidad una sociología de la cultura. Tal vez lo consideraron así porque para entonces la inmensa mayor parte de los turistas hacía turismo para visitar monumentos y ruinas de la antigüedad y no como acontece ahora para bañarse y dorarse en las playas del Mediterráneo o del Caribe.

En este contexto no es mala idea preguntarse por lo que entendemos por cultura porque no parece que se trate de un concepto claro. Hay un concepto periodístico de cultura según el cual los espectáculos musicales son manifestaciones culturales como también lo son el teatro, la ópera, las exposiciones de pintura o de escultura o incluso las obras de la arquitectura. Para el vulgo, cultura es cine, teatro, espectáculos y poco más. Se trata de un concepto reduccionista de uso habitual en prensa, radio, televisión e Internet. Pero nosotros sospechamos que cultura es algo más. Para nosotros cultura es un concepto más amplio y también más noble aunque sea más ignorado.

Ante todo digamos que la cultura es la seña de identidad del hombre como especie diferenciada. Como dice el filósofo español Emilio Lledó (2013), "no hay, tal vez, un término que caracterice tan radicalmente a la vida humana como la palabra 'cultura'. Hay, por supuesto, una realidad, un concepto previo, base de todo el desarrollo cultural: el lenguaje. Sin él no crece ni se desarrolla la cultura". Para Lledó, el hombre es el animal que habla, y habla porque tiene capacidad de abstracción. Y porque tiene capacidad de abstracción es capaz de representarse mentalmente lo que ve, lo que observa, lo que siente, lo que oye, lo que toca. La realidad entra en los animales por medio de sus sentidos pero solo el hombre, gracias a su lenguaje, es capaz de interpretarla y de comunicarla a los demás. "En esa manera de ver las cosas, de sentirla, de articularlas y comunicarlas consiste la cultura", piensa Lledó, una palabra, seguimos citando al pensador, "al menos en la tradición latina que nos la ha entregado, significa 'cultivo', 'trabajo'. 'labor, 'beneficio de la tierra”. Pero cultura, además de cultivo de la naturaleza tierra, es cultivo de la naturaleza humana, es transformación del hombre que habla, el cual "es el principio y origen de la cultura" (Lledó), de modo que volvemos a la idea inicial, la de que la cultura define al hombre, la de que la cultura es un producto humano. $\mathrm{Y}$ de que ha sido por obra y gracia de su trabajo en la naturaleza, en la inanimada y en la animada, por lo que existe el hombre como especie diferenciada y mentalmente (culturalmente) en evolución. Porque "la naturaleza humana empezó siendo un campo que requería, en el estadio original y primero de sus existencia, la siembra y las semillas adecuadas" como sostiene el ya citado Lledó, el cual continúa diciendo: "De ahí el genial invento de la paideia, de la educación. Paideia era un sustantivo relacionado con el verbo paideuo, 'nutrir', y sobre todo 'educar', 'enseñar' 'instruir' [...] En los seres humanos, el territorio de la siembra y del cultivo tiene una restricción esencial la tierra nodriza es, sobre, todo, nuestro cuerpo, la naturaleza, la materia, la carne, el organismo que somos. (...) Es imprescindible una nueva reflexión sobre eso que hemos convertido en palabra usual y, en todo caso, cada vez más lejana: la cultura como fuerza educadora, transformadora, alentadora, esperanzadora" (Lledó, 2013: 22-28).

Seamos coherentes con tan certeras reflexiones y llamemos cultura al proceso transformador de la naturaleza, de toda la naturaleza, incluido el mismo hombre, ese animal racional dotado de lenguaje, imaginación y razón que se hace a sí mismo al tiempo que transforma su entorno. El filósofo José Ortega y Gasset lo expresó con una brevedad certera: el hombre no tiene naturaleza, tiene historia. Digamos amparados en él que la historia junto con la cultura es la segunda naturaleza del hombre. ¿O tal vez la primera?.

Pero evitemos excluir lo negativo, lo perverso, lo malo. No seamos maniqueos. Evitemos la tentación de reducir el mundo a la cristiana virtud de la eutrapelia. La cultura es todo lo que el hombre ha creado y transformado y ha puesto a su servicio. Ha creado un aparato productivo al servicio de sus necesidades. Ha creado instituciones al servicio de su vida en sociedad. El continuo desarrollo de sus primeros eslabones ha conducido a la satisfacción de sus necesidades y a la creación de otras para mantener en marcha las instituciones sociales y 
el aparato productivo. El hombre es el ser más evolucionado de la naturaleza y, por ende, el nuevas porque la producción se paralizaría sin el aliciente del consumo. La especie humana es la especie mejor dotada para el consumo (Georges Bataille, 1962) El aparato productivo está al servicio de las necesidades pero sin las necesidades no habría aparato productivo. La obsolescencia programada es un artilugio entre otros al servicio del mantenimiento del aparato productivo al que necesitamos y que nos necesita.

Pero no solo se echa mano de la obsolescencia programada como fórmula eficaz para destruir lo producido a fin de que deje lugar para que tenga sentido la nueva producción. Hay otras opciones encaminadas a la destrucción de riqueza. Tenemos las guerras, el lujo, los duelos, las huelgas, la sexualidad no reproductiva, la castidad, las distracciones, el deporte, el entretenimiento, los vicios privados (Bertrand de Mandeville, 1714), las epidemias, la drogadicción (G. Bataille, 1962). En definitiva tenemos el consumo, es decir, el consumismo como fenómeno social propio de las sociedades opulentas. El consumo pero no solo de bienes y servicios de primera necesidad sino también de aquellos bienes y servicios que empiezan siendo de lujo y terminan siendo vitales siendo sustituidos por nuevos bienes y servicios de lujo en un proceso continuo.

¿Y no es el turismo una forma de consumo como sostienen los turisperitos desde hace siglo y medio? Una introspección en la literatura acumulada dedicada al turismo insiste tanto en la dimensión consumista del turismo que no ve otra hasta el punto de olvidar la dimensión productiva a la que ayuda a sostener. El turista para la turispericia es un consumidor y nada más que un consumidor, más aun, el turista es el paradigma del consumidor. Y, como todo consumo exige la producción en tanto que, de momento, ignoramos quien produce el turismo, los turisperitos han resuelto el enigma postulando que es el turista produce el turismo al mismo tiempo que lo consume. Pero no adelantemos acontecimientos. De momento nos quedarnos con la idea de que el turismo es una actividad de consumo y el turista un agente meramente consumidor. Dicho de otro modo: para la turispericia, el turismo es una actividad de consumo que nació como un componente propio de la cultura y como un instrumento al servicio de la cultura.

\section{3b. El turismo es economía y forma parte de la economía}

La economía como el turismo tiene dos dimensiones. Una es la realidad, los hechos, y otra su interpretación, la teoría. Dejando fuera de nuestra ocupación el hecho evidente de que la realidad es interpretación, lo cierto es que unas veces llamamos turismo y economía a sendas parcelas de la realidad y otras a las disciplinas que se constituyen con las aportaciones de quienes las estudian. Si se afirma que el turismo es una forma de consumo, como queda dicho, y el consumo es una actividad que forma parte de la realidad que estudia la economía, podemos concluir que el turismo es una actividad económica y, por tanto, su estudio es objeto de la economía.

El turismo como disciplina estudia la realidad turística con una visión centrada en el turista, el cual como hemos dicho se caracteriza por producir turismo en el mismo acto de su consumo. Como explicación, no cabe duda de que los turisperitos han aportado una fórmula sin duda ingeniosa y admirable para poder mantener su visión sujetiva del turismo hasta el punto de cuadrar el círculo sosteniendo que si bien todo consumo exige producción, en el caso del turismo se trata de dos actividades sincrónicas cuando las demás actividades de consumo son posteriores a las actividades de producción. Desde 1988 venimos denunciando esta grave anomalía en la disciplina de turismo. Una anomalía que se mantiene en la medida en la que la visión conceptual convencional define los bienes y servicios turísticos como aquellos que son consumidos por los turistas, elevando a los turistas a la condición del nuevo rey Midas que todo lo que toca lo transustancia en turístico. Para Hunziker y Krapf (1942), el turismo es una disciplina híbrida de sociología y economía, más cercana a 
la sociología que a la economía. Su gran manual de 1942 consta de nueve capítulos, pero, sorprendentemente, el más voluminoso es el noveno, el que se dedica a la economía del turismo. El capítulo nueve ocupa más de la mitad de la obra. Aun así, los citados economistas suizos no dejaron de sostener que el turismo es sobre todo sociología y, afinando más, sostuvieron que el turismo debe ser estudiado como una sociología de la cultura. Todos los turisperitos que les siguieron hasta nuestros días elevan a la categoría de ley indiscutida e indiscutible que el turismo es parte de la sociología. Hoy podrimos decir que, en la medida en que el turismo es cultura y forma parte de la cultura, es la antropología cultural la ciencia que debería ocuparse del conocimiento del turismo, sobre todo la subespecie que se conoce como antropología económica. La antropología cultural se ocupa de estudiar las instituciones sociales de los diferentes pueblos que vivieron en el pasado y también de los que viven en el presente. La antropología cultural, también conocida como social, es la rama de la antropología que centra su estudio en el conocimiento del ser humano por medio de sus costumbres, relaciones sociales y con su entorno, estructuras políticas y económicas, urbanismo, medios de alimentación, salubridad, creencias y ocupación del tiempo libre. La antropología, como la sociología, es una ciencia empírica basada en la observación de la realidad objeto de estudio que se basa más en descripciones que en elucubraciones teóricas. La antropología cultural no suple la tarea propia de las ciencias económicas y por esta razón hay antropólogos culturales que son también excelentes economistas como es el caso de Maurice Godelier (1969) para quien en las sociedades primitivas las relaciones de parentesco funcionan como relaciones de producción, relaciones políticas y esquema ideológico. La antropología cultural toma mucho del pensamiento de Marx-Engels y destaca en sus investigaciones el papel del modelo de producción hegemónico en cada sociedad. Esta es la razón de que hoy tengamos antropólogos que se ocupan del turismo en la medida en la que, como hemos dicho, el turismo es una institución cultural relacionada con la recreación y el uso del tiempo libre.

En definitiva, el turismo es economía y forma parte de la economía. Es economía porque los turistas son agentes económicos que son productores y son consumidores, los cuales, gracias a la dignificación del trabajo, han conseguido que en su contrato de trabajo se les reconozca el derecho a tener un periodo de tiempo de vacaciones remuneradas, un periodo de tiempo durante el que dejan de ser productores para dedicarse a ser solo consumidores de bienes y servicios fuera de su lugar de residencia, lo que implica que consuman programas de estancia con contenido (Muñoz de Escalona, 1988, 1991, 2011, 2013) Pero aun hay más: ese consumidor desplazado que es el turista es un agente económico cuya propensión al consumo en su lugar de residencia habitual experimenta un aumento significativo cuando se encuentra fuera del mismo. Nadie se ha dedicado todavía a investigar con ayuda de la econometría este efecto del turismo en la propensión marginal al consumo. Urge que se llegue a cuantificar en tantos casos como sea necesario para confirmarlo. Entre tanto podemos suponer que el turismo no solo es consumo sino que también incrementa el consumo y, por ende, la producción. En definitiva, el turismo implica nuevas necesidades, las cuales están al servicio de mantener y fomentar el sistema productivo, cuyo desarrollo se pone al servicio del sistema consuntivo en un proceso que se realimenta sin fin. $\mathrm{O}$ con el fin que fije la necesaria conservación de la naturaleza.

\section{Una nueva cuestión inquietante, la epistemología del turismo}

El turismo, como todo fenómeno social, es sin duda multidimensional. Partiendo de esta base, es habitual en la comunidad internacional de turisperitos propugnar la imperiosa necesidad de estudiarlo con ayuda de todas las ciencias sociales disponibles. Una, la sociología, se ocupa (o debería ocuparse) de investigar las relaciones que surgen entre los visitantes y los visitados, un tema de investigación de naturaleza empírica y casuística en base 
a cuyos resultados no es posible inducir leyes de validez universal. Lo mismo acontece con la geografía, disciplina que estudia la innegable dimensión espacial del turismo, tanto del colectivo humano que lo practica como de los prestadores de servicios a dicho colectivo. Y no digamos la historiografía, $y$, por supuesto la antropología, ciencias todas ellas basadas en estudios de casos cuyas conclusiones no pueden aspirar a ser de aplicación general como muy bien demuestran las aportaciones de Popper (1998) sobre la incapacidad de la inducción de cara a la construcción de fundamentos científicos sólidos.

Con respecto a la declaración de intenciones del editor, el ldo. Korstanje, lo primero que podemos comentar es que para responder de forma minuciosa a sus afirmaciones se necesita disponer de mayor espacio del usual en un ensayo monográfico breve. Empecemos por el párrafo final. El ldo. Korstanje, sostiene de forma contundente que.

es necesario crear (fundar) una nueva epistemología del turismo que contemple cuestiones antropológicas, sociales, psicológicas y sobre todo arqueológicas e históricas. Partiendo de la base que el "hecho turístico" denota una gran importancia para las estructuras culturales de las diferentes sociedades, invitamos al siguiente número especial [de esta revista] a autores, investigadores y estudiantes preocupados por cuestiones epistemológicas y metodológicas del turismo.

Lo primero que se nos ocurre es preguntar por la existencia de la epistemología del turismo. Si existe, ¿cómo es? y, a continuación, ¿Cuáles son sus aportaciones? A la segunda pregunta es más fácil responder que a la primera, pero es obvio que después de responderla, también habremos respondido implícitamente a la primera. Como veremos más adelante, la epistemología no se ha ocupado aún del corpus teórico del turismo. De aquí que tengamos que afirmar que la respuesta a la primera pregunta no puede ser más que negativa. Aclaremos que el campo epistemológico existe, lo que aún no existe es su plena aplicación al turismo. Las anomalías científicas que pesan sobre el turismo desde sus orígenes allá por el último tercio del siglo XIX se explican por esta ausencia.

El mismo editor nos pone en la pista certera para reflexionar sobre la segunda pregunta con estas palabras:.

en los últimos años, el estudio sistemático del turismo ha producido un corpus de saberes interdisciplinario que puede observarse en la cantidad de tesis de doctorados, masters, revistas (casi 200 en la actualidad según CIRET) e instituciones, empero ha fallado para construir un corpus disciplinario científico (Monterrubio, 2011).

Obviamente, si el turismo se concibe como un fenómeno multidimensional, lo lógico es que el corpus de saberes que lo toma como objeto de estudio sea también interdisciplinar, o, mejor, multidisciplinar. Y así acontece, en efecto. Y, para constatarlo, basta con echar una somera ojeada a la abundante bibliografía acumulada desde fines del XIX a la actualidad, o al esquema curricular de cualquier centro académico dedicado a impartir los conocimientos aportados por ella. Hay en el stock bibliográfico disponible obras de sociólogos, geógrafos, historiadores, antropólogos, especialistas en marketing, economistas y hasta, últimamente, de biólogos, medioambientalistas, museólogos, expertos en deportes, arquitectos, publicistas, gastrónomos, expertos en organización de eventos, expertos en parques temáticos y, como suele decirse, un más que largo etcétera que no parece tener fin ya que la serie de estudiosos es de esperar que siga aumentando si nadie lo remedia en el inmediato futuro. Habrá quien piense, como es el caso de Jafar Jafari, que esto es altamente positivo, tanto que es considerado, por raro que pueda parecer, como un indicador de su indudable cientificación. Lo refleja con claridad esta frase de nuestro editor:.

[el estudio sistemático del turismo ha producido un corpus de saberes interdisciplinarios provocado] en parte por la carencia de un objeto específico de estudio y en parte por la falta de una metodología unificadora. Durante mucho tiempo, los turismólogos [sic] han creído erróneamente que el grado de maduración de una disciplina depende de la cantidad de investigaciones en determinado tema. Entre ellos se encuentra sin duda el citado Jafari. 
Pero volvamos al texto del editor de este número especial de la revista Tiempo Libre y Turismo y transcribámosla completa ya que dicho texto es más que una simple invitación para adentrarse en el meollo de la cuestión. El ldo. Korstanje expone en él lo que sigue:.

El turismo como hoy lo conocemos es una institución que representa la respuesta cultural, en una sociedad compleja e industrial, a la necesidad de tomar distancia y distraerse. Nuestra postura no solo complementa el legado del padre de la antropología cultural [B. Malinowski], sino que además focaliza en aspectos que no han sido aún abordado por los cientistas sociales que se dedican a estudiar el turismo. La comprensión del turismo como una institución cultural y social que a lo largo de los años, y dependiendo de las organizaciones políticas y sociales ha tomado diferentes formas, se corresponde con elaboración de una teoría científica que permita estudiar los diferentes sistemas oníricos de cada sociedad, sus elementos y su complicidad con otras partes de la estructura social. En otras palabras, una nueva epistemología del turismo como hecho social, único y comparable a sociedades no occidentales y/o civilizaciones extintas. Si en el siglo XV a este acto de descanso se lo llamaba viaje, en lugar de viaje turístico sólo aplica a una cuestión de forma pero no de sustancia. Aun cuando el término turismo sea más o menos novedoso, no rastreable a la antigüedad, existen indicios importantes por medio de las cuales se han observado formas de viajes recreativos, ordenados y legalizados por el poder estatal que ameritaban sus respectivos retornos. Los romanos antiguos habían tejido toda una serie de carreteras, impuesto formas legales de descanso (feriae), para fomentar los viajes a familiares o por esparcimiento (Paoli, 1975). Nuestro etnocentrismo como modernos radica en pensar que nuestras prácticas son únicas de nuestro tiempo y no han sido seguidas por otros grupos humanos.

Por otro lado, en los últimos años, el estudio sistemático del turismo ha producido un corpus de saberes interdisciplinario que puede observarse en la cantidad de tesis de doctorados, masters, revistas (casi 200 en la actualidad según CIRET) e instituciones, empero ha fallado para construir un corpus disciplinario científico (Monterrubio, 2011). En parte por la carencia de un objeto específico de estudio, y en parte por la falta de una metodología unificadora. Durante mucho tiempo, los turismólogos [sic] han creído erróneamente que el grado de maduración de una disciplina depende de la cantidad de investigaciones en determinado tema. El psicoanálisis, sin ir más lejos, [un] caso que refuta ese pensamiento, se ha consolidado en apenas 15 años, mientras otras disciplinas como el Management o el turismo llevan varias décadas produciendo material inconexo, sin una metodología fija (Muñoz de Escalona, 2010; Castillo Nechar y Panoso Netto, 2011; Maximiliano Korstanje, 2008; 2011; Alistair Thirkettle \& M. Korstanje, 2013). Si se nos pregunta qué estudia la sociología, responderemos las normas sociales, lo mismo ocurre con la psicología respecto a la personalidad, o la antropología con la cultura. Empero ¿qué estudia el turismo?, ¿la hospitalidad?, ¿los rituales de desplazamiento?, ¿la recreación, el ocio o el descanso?, ¿el patrimonio?, ¿una forma o instrumento de alienación puramente capitalista? o ¿todo eso junto? En términos prácticos existe una suerte de indisciplina en el estudio del turismo que no permite la creación de paradigmas unificados de pensamiento (Tribe, 1997).

En consecuencia, es necesario crear (fundar) una nueva epistemología del turismo que contemple cuestiones antropológicas, sociales, psicológicas y sobre todo arqueológicas e históricas. (el subrayado es nuestro) Partiendo de la base que el "hecho turístico" denota una gran importancia para las estructuras culturales de las diferentes sociedades, invitamos al siguiente número especial a autores, investigadores y estudiantes preocupados por cuestiones epistemológicas y metodológicas del turismo.

Ya hemos dicho que la epistemología no debe confundirse con la metodología. El método no es otra cosa que el camino elegido para conseguir un fin, en nuestro caso el conocimiento científico de un fenómeno o realidad. Cada investigador es muy dueño de utilizar el que considere como más eficaz. Por metodología entendemos la teoría del método. La consolidación de una ciencia implica el hecho de que ha desarrollado un método propio e 
intransferible. Hay, pues, tantos métodos y metodologías como ciencias consolidadas y, en consecuencia, hay muchas a disposición de la construcción del conocimiento del turismo. No obstante, ninguna es específica y propia de esta disciplina. Los estudiosos del turismo se sirven en cada caso de alguna o de un mix de las metodologías disponibles para sus propósitos. Es en este extremo en el que se basa la afirmación de que no existe, ni puede existir, un ciencia específica del turismo, la que fue llamada turismología por el geógrafo yugoslavo Zivadin Jovicic (1975), como si fuera una ciencia autónoma e independiente de aquellas ciencias sociales que le prestan sus métodos específicos de investigación. Por ello lo que existe son diferentes ciencias aplicadas al turismo, las cuales suelen tomar el nombre de la ciencia social en la que se basan.

Pero así como hay una multitud de ciencias turísticas porque existe una multitud de metodologías disponibles a disposición de los investigadores, no puede decirse lo mismo de la epistemología. La epistemología, entendida como teoría del conocimiento no se ha ocupado ni se puede ocupar del turismo en la medida en la que, como queda dicho, el turismo no es una ciencia en el sentido duro del término. ¿Contaremos en el futuro con investigaciones dedicadas a la epistemología del turismo? No es que haya que crear o fundar una nueva epistemología del turismo porque tal cosa carece de sentido. Lo que tiene sentido es la epistemología de la sociología, de la economía, de la geografía, es decir, de aquellas ciencias sociales desde las que se construye el conocimiento del turismo como fenómeno social. El conocimiento del turismo se construye con un mix de epistemologías relativas a la economía, la sociología o la antropológica habida cuenta de sus diferentes dimensiones y en función de la supuesta complejidad de la materia, una complejidad que no es más que la consecuencia ineluctable de esa misma convicción, la cual lleva a propugnar el necesario uso indiscriminado de todas las ciencias a la vez.

\section{El turismo concebido como actividad productiva única y perfectamente identificada}

Hasta ahora nos hemos mantenido en el seno de la concepción convencional del turismo como fenómeno social y, de acuerdo con tal conceptualización hemos llegado a la conclusión de que, en la medida en la que no se puede hablar de una ciencia del turismo tampoco se puede hablar de una epistemología propia de tal ciencia inexistente. Pero el turismo puede ser conceptualizado no solo como fenómeno, lo que se ve, sino también como una especie de noúmeno, como lo que no se ve porque no es evidente habida cuenta de que las conceptualizaciones al uso no lo evidencian, es decir, no lo ponen de manifiesto. La investigación a la que nos venimos dedicando desde 1985 en el antiguo Instituto de Economía y Geografía del CSIC, España, consiste en demostrar que si el turismo es consumo según los llamados padres del turismo es porque antes de ello es producción. No hay consumo sin producción, ni siquiera cuando esta consistía en la recolección de frutos y en la caza y en la pesca. Recolectar, cazar y pescar son actividades productivas y como tales previas a las actividades consuntivas. La doctrina convencional del turismo, de raíz sociológica, contempla también la producción, a la cual incardina en el sector servicios de la economía, pero esa doctrina es incapaz de identificar el turismo como una actividad productiva diferenciada ya que la visión desde el turista exclusivamente como consumidor conduce, ineluctablemente, a un conjunto heterogéneo de actividades productivas, algo que, en pura lógica implica la indeterminación. No es posible diferenciar las actividades productivas en función del consumidor y mucho menos cuando ese consumidor está tan mal identificado como lo está el turista.

Por lo antes dicho, si tenemos necesidad de identificar la producción de turismo como una actividad productiva perfectamente identificada tenemos que volver a observar la realidad más allá de lo evidente, es decir, de lo inmediato. La doctrina convencional, de etiología vulgar como hemos demostrado en nuestras publicaciones, se basa en la enumeración y descripción de la conducta de quien realiza un tur sea este de ocio o de negocio. Es así como 
pone el énfasis central en las características del sujeto, sobre todo en sus motivaciones y en todo aquello que hace, desde los desplazamientos hasta las estancias en los lugares visitados. Pero cabe llevar a cabo una observación de la realidad diferente. Llevemos a cabo antes una serie de reflexiones previas:.

Las apariencias no agotan la realidad. Los sentidos son una fuente de conocimiento válido pero no suficiente porque no nos revelan lo que hay detrás del fenómeno, lo que Emmanuel Kant llamó noúmeno. El noúmeno es lo que, estando oculto, pasa desapercibido por los sentidos. Por esta razón para acceder a ello hay que prescindir de los sentidos y buscar otra vía de conocimiento. Esa vía es el intelecto, la razón, la capacidad de abstracción que el hombre adquirió en una fase avanzada de su evolución. Incluso la intuición tiene un papel que jugar en esta ocasión. La razón ha demostrado su capacidad para desvelar lo oculto o, al menos, eso es lo que ha sido aceptado por la comunidad científica siendo la base del conocimiento. La razón se nutre de la lógica y la lógica se nutre de postulados desde los cuales es posible avanzar respetando las reglas estrictas de la construcción cognitiva. Así es como el conocimiento científico, el que va más allá de los sentidos y de la mera descripción de las apariencias logra desvelar lo oculto, la esencia de las cosas, su dimensión nouménica, la realidad de las cosas más allá de lo que percibimos por los sentidos e independientemente de nuestra experiencia. Kant las llama las cosas en sí mismas. Kant advierte de que el hombre no puede conocer las cosas como son en sí mismas, lo que él llama el noúmeno. El hombre solo puede conocer las apariencias de las cosas, es decir, el fenómeno. Es por ello que para el conocimiento de la realidad no tenemos otra vía que esforzarnos en comprender cada vez más y mejor el proceso mismo de la experiencia.

¿Significa lo que acabamos de decir que al hombre le está vedado el conocimiento nouménico de la realidad, de las cosas en sí mismas? ¿Está condenado el proceso de la construcción del conocimiento científico a quedarse en un saber meramente descriptivo de las apariencias? Parece que no tenemos más alternativa que responder afirmativamente a tan inquietante pregunta, pero, reconocida esta limitación, hemos de reconocer también que incluso en el conocimiento como mera descripción de las apariencias hay muchos niveles, desde el más superficial, el propio del vulgo, al que va más allá, el propio de los científicos, un nivel al que llamamos de excelencia, sin desdeñar los niveles intermedios, aquellos que son los propios de las pseudo-ciencias, los de las ciencias falsas y los de las ciencias en estadios de desarrollo insuficiente. El sociólogo francés Pierre Bourdieu (2013) se refiere a este proceso cognitivo con esta frase:.

Aún no se ha considerado la función de ruptura que Durkheim atribuía a la definición previa del objeto como construcción teórica "provisoria" destinada ante todo a "sustituir las nociones del sentido común por una primera noción científica'. En efecto, en la medida en que el lenguaje común y ciertos usos especializados de las palabras comunes constituyen el principal vehículo de las representaciones de la sociedad, una crítica lógica y lexicográfica del lenguaje común surge como el paso previo indispensable para la elaboración controlada de las nociones científicas (ob. cit. p. 30).

Más adelante, Bourdieu insiste en esta misma idea con las siguientes palabras:.

Es sabido que el acto de descubrir que conduce a la solución de un problema sensoriomotor o abstracto debe romper las relaciones más aparentes, por ser las más familiares, para hacer surgir el nuevo sistema de relaciones entre los elementos. En sociología, como en otros campos, "una investigación seria conduce a reunir lo que vulgarmente se separa o a distinguir lo que vulgarmente se confunde". La sociología no puede constituirse como ciencia efectivamente separada del sentido común sino bajo la condición de oponer a las pretensiones sistemáticas de la sociología espontánea la resistencia organizada de una teoría del conocimiento de lo social cuyos principios contradigan, punto, por punto, los supuestos de la filosofía primera de lo social (ob. cit.: 31-32).

Dicho lo que antecede y admitido el hecho de que el turista es un consumidor tenemos 
que admitir antes de serlo se ha tenido que comportar como productor. ¿Pero productor de qué? Para responder a esta pregunta tenemos que responder antes a otra. ¿Qué es lo consume un turista? La doctrina convencional o sociológica responde que un turista consume un conjunto de servicios a los que considera por este mero hecho turísticos, pero, como ya hemos dicho, se trata siempre de servicios no solo muy diversos sino también implícitamente sometidos al criterio de su mayor o menor frecuencia de consumo por parte del turista. Sin embargo, ahondando más como decimos en la observación nos percataremos de que lo que consume un turista es un programa de estancia con contenido y que tal programa de estancia exige unas actividades preparatorias previas que alguien tiene que realizar antes de que sea consumido, unas actividades que requieren conocimientos, tiempo y asignación de recursos escasos. En definitiva, todo lleva a admitir que se trata de una actividad productiva.

Las diferentes disciplinas que se vienen ocupando del conocimiento del hecho turístico se caracterizan por exponer sus diferentes dimensiones en niveles que se quedan en la mera descripción de aquello que es más aparente y superficial del mismo, es decir, en su fenomenología primera, la que se percibe por medio de los sentidos sin posterior elaboración intelectual de sus aportaciones Podríamos ofrecer una gran profusión de citas que servirían para constatar de forma contundente lo que acabamos de decir. Pero recordemos la cita de Korstanje sobre los tres elementos que, a su juicio, definen el turismo. Sin duda, M. Korstanje exhibe en ella una visión muy bien formalizada y sin duda acorde con los hábitos tradicionales de los investigadores del turismo, pero no es menos cierto que su explicación no logra levantar el vuelo rasante de la mera descripción, tan frecuente en la bibliografía del turismo (Korstanje, 2011).

Podemos preguntarnos si entra dentro de los posible ofrecer una descripción del turismo que despegue de las apariencias más inmediatas para ir más allá de ellas ofreciendo una descripción de aspectos progresivamente más profundos hasta aproximarse a lo nouménico, a la esencia del turismo. Como respuesta podemos manifestar que los resultados de la investigación que venimos desarrollando desde 1985 indican que tal cosa es posible. Ahí están nuestras publicaciones. La primera data de 1988. En ellas se puede ver que hemos ido más allá de lo meramente superficial del turismo para aproximarnos a sus aspectos más ocultos. Nuestra respuesta consiste en destacar una fase que los turisperitos olvidan, la fase de la programación de los viajes, una fase que es, obviamente, previa e imprescindible al llamado hecho turístico como tal hecho sociológico, el desplazamiento físico de ida y vuelta con fines de ocio o de negocio para satisfacer necesidades fuera de la residencia habitual. Procede, pues, volver a preguntarse si esta actividad programadora tiene el carácter de una actividad productiva en sí misma. La respuesta puede darla el hecho de que hay actividades de planificación desarrolladas por empresas tanto públicas como privadas cuyos outputs son utilizados como inputs en otras actividades productivas en las que se obtienen nuevos outputs. Ahí están los estudios de arquitectura, los bufetes de abogados, las consultorías y las gestoras en general, las cuales son actividades productivas de servicios perfectamente definidas cuyos outputs son inputs de otras que decidieron en algún momento externalizarlos por razones de eficiencia y reducción de costes. Por ello no es ninguna fantasía ver al turismo como la actividad productiva que se dedica a producir justo lo que consumen los turistas, programas de estancia con contenido, una actividad productiva que, como todas las demás, nació en la economía doméstica y unas más pronto y otras más tarde, pasaron a ser desarrolladas en empresas mercantiles especializadas. En el caso del turismo esto ocurrió a mediados del siglo XIX con la empresa que fundó Thomas Cook en Leicester (Inglaterra) en 1852, empresa a la que siguieron otras similares tanto en Europa primero y en Estados Unidos después para generalizarse más tarde en todo el mundo, empresas que no son meras intermediarias como creen los turisperitos sino productoras de turismo siguiendo una tecnología específica. No obstante, la producción de turismo aún sigue mayoritariamente alojada en la economía doméstica. Las nuevas tecnologías de la información están reforzando y 
prolongando la producción doméstica de turismo pero eso no está obstaculizando el desarrollo de la producción mercantil de turismo.

Y ahora viene la última pregunta: ¿Tiene algún sentido hablar de epistemología del turismo considerado como actividad productiva única y perfectamente identificada? La respuesta no puede ser otra que la negativa pues estamos hablando de una ingeniería especializada, la ingeniería del turismo, en la que, obviamente, la epistemología no juega papel alguno.

\section{A modo de conclusión provisional}

La bibliografía del turismo puede ser vista a la luz de la polémica de Durkheim contra el artificialismo, el psicologismo o el moralismo, a lo que nosotros añadiríamos el propagandismo, lo cual no es sino el revés del postulado según el cual los hechos sociales "tienen una manera de ser constante, una naturaleza que no depende de la arbitrariedad individual y de donde derivan las relaciones necesarias" (cit. por Bourdieu, ob.cit. p. 32) La mera descripción del turismo en sus fases superficialmente físicas sería el primer obstáculo que caería desde el momento en que se enjuiciara el corpus teórico disponible por medio de una epistemología del turismo digna de ese nombre. Cuando llegue ese día habremos dado vía libre a la existencia de diferentes ciencias aplicadas al turismo, cada una dedicada a estudiar cada uno de sus aspectos pero sin mezclarlos, lo cual no empecé para que las aportaciones obtenidas en unas sean tenidas en cuenta por otras.

Pretendemos con este artículo dirigirnos a la turispericia para que reflexione sobre la improcedencia de desarrollar una epistemológica del turismo en tanto que ni los planteamientos convencionales que lo conciben como un fenómeno ni los alternativos que lo ven como una actividad productiva la necesitan. Es de resaltar la tendencia cada vez más nítida entre los turisperitos a desarrollar trabajos adornados con las herramientas más sofisticadas aplicadas a un bagaje conceptual que hace aguas por doquier. La obsesión por la epistemología es una de ellas, una más de las que no necesita la disciplina a no ser por el hecho de que la profesión de muchos turisperitos se lleva a cabo en las universidades y no en las empresas. Aplicar sofisticados planteamientos al turismo recuerda a lo que decía el eminente economista español Antonio Flores de Lemus (1876-1941) con respecto a la aplicación de métodos muy exigentes a los estudios de economía hechos con datos estadísticos deficiente, que es tan absurdo como pesar leña con balanza de precisión. Si así dejamos de hacerlo abandonaremos la insistencia en la sospechosa importancia que se le otorga al turismo y seremos más modestos, alejándonos del deleznable propagandismo que mina la disciplina al servicio no de su eficacia práctica sino de los intereses empresariales y políticos, intereses sin duda legítimos, pero que no deben ser servidos por los investigadores. La alegre afirmación infundada de que el turismo es la primera industria mundial está al servicio de esos intereses. Esa afirmación se sostiene en los dogmas del enfoque convencional, pero con toda seguridad sería insostenible en base a un conocimiento del turismo plenamente respetuoso con las exigencias de la eficacia. Urge ponerse manos a la obra.

\section{Bibliografía.}

BATAILLE, G.

1962 La parte maudite prècede de La notion de depènse. Editions de Minuit. Paris (Hay traducción española en Icaria, Barcelona 1987, traducción de F. Muñoz de Escalona).

BERNECKER, $\mathrm{P}$.

1954 Tourism in classical Era. Revue de Tourisme, oct/dic. .

BOURDIEU, P; CHAMBOREDON, J-C y PASSERON, J-C.

2013 El oficio de sociólogo. Presupuestos epistemológicos. Siglo XXI de España. Madrid.

CASTILLO. M y PANNOSSO, A.

2010 Epistemología del turismo. Editorial Trillas. México D F. 
DUMANZEDIER, $\mathrm{J}$.

1968 La civilización del ocio Ediciones Guadarrama. Madrid.

JOVICIC, Z.

1975 Pour et contre la turismologie comme discipline scientifique distincte. Editions Gurten, Berna.

KRAFT, K.

1954 La notion de tourisme. Revue de Tourisme, 2: 50-56.

KORSTANJE, M. E.

2008 "El ocio como elemento de construcción identitaria y uniculturalismo en el Imperio Romano". Culturales, 4(7): 101-150.

2011 "Mitología y turismo: La exégesis como interpretación hermenéutica". Estudios y perspectivas en turismo, 20(6): 1258-1280.

2012 “Odin el Dios Viajero: La influencia de la Mitología Nórdica en la creación del Turismo". Turismo e Sociedade, 4(2): 1-19.

GODELIER, $\mathrm{M}$.

1969 Las sociedades primitivas y el nacimiento de las sociedades de clases según Marx y Engels: Un Balance Crítico. Bogotá: La Oveja Negra.

HUNZIKER, W. y KRAPF, K.

1942 Grundriss der algemeinen Fremdenverkehrslehre. Zurich: Polygraphischer Verlag.

LLEDÓ, E.

2013 Palabras de la cultura en Los libros y la libertad. RBA, Barcelona.

MANDEVILLE, B,

1982 La fábula de las abejas o como los vicios privados hacen las virtudes públicas. Madrid: Fondo de Cultura.

MUNOZ DE ESCALONA, F.

1988 Economía de la producción turística, hacia un enfoque alternativo. Información Comercial Española, nov.

2010 "Epistemología del turismo. Un estudio múltiple". Turydes, 3, 7.

2011 Autopsia del turismo. Editorial Académica Española. Saarbrüken. Alemania.

2013 Crítica de la economía turística. Enfoque de oferta versus enfoque de demanda. Publicia. Saarbrücken. Alemania y en http://www.eumed.net/tesis-doctorales/fme/index.htm (1991).

ORTEGA y GASSET, J.

2012 Obras selectas. Madrid: Gredos.

OSSIPOWE P.

1951 Contribution a la notion de tourisme. Revue de Tourisme, 2: 71-73.

POPPER, K.

1986 La lógica de la investigación científica. Editorial Laia. Barcelona.

1998 Los dos problemas fundamentales de la epistemología. Editorial Tecnos. Madrid.

THIRKETTLE, A., y KORSTANJE, M. E.

2013 "Creating a new epistemiology for tourism and hospitality disciplines". International Journal of Qualitative Research in Services, 1(1), 13-34. 